assessment of standards recommended by the March 2011 IOM Standards for Systematic Review.

Implications for Guideline Developers/Users The proliferation of systematic reviews provides guideline developers the opportunity to utilise pre-existing research to produce evidence-based guidelines. However, the wide variation in quality means developers will need to carefully assess the quality of systematic reviews using a tool such as DART.

\section{P155 LESSONS LEARNED: APPLYING GRADE METHODOLOGY TO EVIDENCE-BASED HEALTH TECHNOLOGY ASSESSMENT WITHIN A MANAGED CARE SETTING}

J Lam. Kaiser Permanente, Southern California Permanente Medical Group, Pasadena, USA

\section{0:1136/bmjqs-2013-002293.185}

Background Health technology assessment (HTA) within the context of a managed care organisation requires rigorous evidence assessment completed in a timely and efficient manner. A modified version of the GRADE evidence grading system was piloted in a long-standing HTA programme to evaluate new and existing medical technologies with high-cost, high-volume impact.

Context An HTA programme developing evidence-based guidance to inform technology acquisition and implementation strategies within a large, US-based healthcare system.

Description of Best Practice A modified GRADE approach was used to assess the quality of evidence for six health technologies over a 6-month period. Although the application of GRADE required additional analytical time, evidence assessments were completed within a reasonable timeframe. Application of the GRADE framework allowed technology committee members to more easily understand the quality of a body of evidence, weigh the benefits and harms, account for patient values, and assess potential resource and operational implications.

Lesson for Guideline Developers Prior to adopting GRADE, many new technologies were assessed as having "insufficient" evidence. The GRADE approach provided greater clarity, and evidence that would previously have been classified as "insufficient" was graded as either "low" or "very low" quality, allowing for greater flexibility and transparency in decision-making when moving from evidence to recommendations. Diagnostic and prognostic tests or devices continued to present unique challenges as well as technologies for which limited comparative evidence was available, and more guidance for in these areas is needed. Additional elaboration on resource and operational concerns specific to evaluating new technologies would be useful to HTA programmes.

\section{P156 CLINICAL PRACTICE GUIDELINES IN PAEDIATRICS IN THE CZECH REPUBLIC}

K Klikova, R Licenik, V Mihal. Centre for Clinical Practice Guidelines, Olomouc, Czech Republic

\section{0:1136/bmjqs-2013-002293.186}

Background High quality clinical practice guidelines in paediatrics (CPGP) should be developed with standard and rigour methods. There are specialty societies in the Czech Republic developing guidelines of variable quality using different methods of development, adaptation, implementation and evaluation
Objectives The aim of this study was to analyse the methods of development, adaptation, dissemination, implementation and evaluation of Czech CPGP.

Methods The database of all CPGP was developed in 2011 and updated on a regular basis. The three types of specialty societies were decided: 1 . Paediatric and neonatology societies 2. Other specialty societies developing CPGP 3. Specialty societies developing guidelines with relevant recommendation for paediatric care. The search and analysis of open resources were made to find the information about guideline methodology. Questionnaire survey to get the missing information was made.

Results There are 113 specialty medical societies in the Czech Republic. 31 societies developed 140 CPGS. 31\% developed by paediatric and neonatology societies, $51 \%$ by other societies and $18 \%$ by societies developing CPGs with some paediatric recommendations. The questionnaire survey is ongoing.

Discussion The methods of development CPGP in the Czech Republic is of low quality. There are no explicit strategies for dissemination, implementation and evaluation.

Implications for Guideline Developers/Users The methods of guideline development need be standardised and should be of highest possible quality. There is already high quality methodology in the Czech Republic developed by National Reference Centre, which has been using by different specialty societies and could be used for CPGP.

\section{P157 CLINICAL PRACTICE GUIDELINES IN THE CZECH AND SLOVAK REPUBLIC}

K Klikova, R Licenik. Centre for Clinical Practice Guidelines, Olomouc, Czech Republic

\section{0:1136/bmjas-2013-002293.187}

Background Palacky University Faculty of Medicine Centre for clinical practice guidelines is the independent academic centre focused on guidelines methodology.

Objectives The aim of this study is to analyse methods of development, adaptation, implementation and evaluation of CPGs in the Czech and Slovak Republic from 2010 to 2013.

Methods The database of all Czech and Slovak CPGs and specialty societies was developed in 2010 and updated on a regular basis. The analysis of methods of development was made. AGREE II instrument was used both in Czech and English version to evaluate quality of some CPGs.

Results There are 112 Czech specialty societies and the national Reference Centre developing CPGs. 1331 CPGS were developed till 2013 in total with increase of 33\% between 2010 and 2013. The number of adopted international CPGs has increased significantly. Majority of CPGs have not stated funding and conflicts of interest. In the Slovak Republic, there are 125 specialty societies and the Ministry of Health developing CPGs. 342 CPGs were developed till 2013. Majority of CPGs were developed by government. A few CPGs stated non-governmental funding, which is always a private company support.

Discussion There has been increasing number of developed CPGs in both countries. Standardised high quality methods are not used systematically. High quality methodology was developed and used by Czech National Reference Centre.

Implications for Guideline Developers/Users There should be high quality methods used for CPG development. The developing bodies should adopt methodology already exist in the Czech Republic. 